\title{
miR-5191 functions as a tumor suppressor by targeting RPS6KB1 in colorectal cancer
}

\author{
HYUN-JU AN ${ }^{1,2}$, MISUN PARK ${ }^{3,4}$, JOON KIM $^{2}$ and YOUNG-HOON HAN ${ }^{1}$ \\ ${ }^{1}$ Division of Radiation Cancer Research, Korea Institute of Radiological and Medical Sciences, Seoul 139-706; \\ ${ }^{2}$ Laboratory of Biochemistry, School of Life Sciences and Biotechnology, Korea University, Seoul 136-701; \\ ${ }^{3}$ Department of Radiological \& Clinical Research, Korea Cancer Center Hospital, Korea Institute of Radiological \\ and Medical Sciences, Seoul 139-706; ${ }^{4}$ Department of Radiological \& Medico-Oncological Sciences, \\ Korea University of Science and Technology, Daejeon 305-350, Republic of Korea
}

Received February 15, 2019; Accepted August 8, 2019

DOI: $10.3892 /$ ijo.2019.4865

\begin{abstract}
MicroRNAs (miRNAs/miRs) are a class of small non-coding RNAs that play pivotal roles in cancer physiology as important epigenetic regulators of gene expression. Several miRNAs have been previously discovered that regulate the proliferation of the colorectal cancer (CRC) cell line HCT116. In the present study, one of these miRNAs, miR-5191, was characterized as a tumor suppressor in CRC cells. Transfection with miR-5191 led to a significant decrease in cell proliferation, invasiveness, tumor sphere-forming ability and tumor organoid growth, as determined via trypan blue, Transwell, sphere culture and organoid culture assays, respectively. Flow cytometric analyses revealed that miR-5191 induced the cell cycle arrest and apoptosis of CRC cells. Additionally, the expression of miR-5191 was downregulated in CRC tumor tissues compared with in normal tissues, as measured by reverse transcription-quantitative PCR analysis. Ribosomal protein S6 kinase $\beta 1$ (RPS6KB1) was identified as a direct target of miR-5191. Ectopic expression of RPS6KB1 suppressed the function of miR-5191. Intratumoral injection of miR-5191 mimic suppressed tumor growth in HCT116 xenografts. These findings suggested a novel tumor-suppressive function for miR-5191 in CRC, and its potential applicability for the development of anticancer miRNA therapeutics.
\end{abstract}

\section{Introduction}

Colorectal cancer (CRC) is the third most common cancer worldwide, with $>1,000,000$ new cases diagnosed annually, accounting for $10 \%$ of all cancer cases (1). It has been

Correspondence to: Dr Young-Hoon Han, Division of Radiation Cancer Research, Korea Institute of Radiological and Medical Sciences, Nowon-gil 75, Nowon-gu, Seoul 139-706, Republic of Korea E-mail: yhhan@kirams.re.kr

Key words: microRNA, microRNA-5191, colorectal cancer, ribosomal protein $\mathrm{S} 6$ kinase $\beta 1$, apoptosis reported that $\mathrm{CRC}$ initiation and progression involve a variety of signaling pathways, such as WNT, transforming growth factor- $\beta$ (TGF- $\beta$ ), receptor tyrosine kinase and mammalian target of rapamycin (mTOR) signaling $(2,3)$. Among these, the mTOR signaling pathway has been shown to serve a crucial role in the development and progression of various human cancers (4-6). Particularly, ribosomal protein S6 kinase $\beta 1$ (RPS6KB1) mediates effects of the PI3K/AKT/mTOR pathway on mRNA translation, cell proliferation, metastasis and angiogenesis (7-10).

MicroRNAs (miRNAs/miRs) are small non-coding RNAs (19-22 nucleotides in length) that negatively regulate gene expression by binding to the 3'untranslated region (3'UTR) of their target mRNAs. Various studies have reported the dysregulation of miRNAs in numerous types of human cancer, including breast cancer $(11,12)$, lung cancer $(13,14)$, and CRC $(15,16)$. In terms of cancer-related functions, miRNAs can be defined as oncogenes or tumor suppressors, depending on their target genes. A number of miRNAs have been reported to function as tumor suppressors in cancer. miR-34 is a well-known tumor suppressor miRNA family that induces apoptosis in various cancers (17-19). miR-15 and miR-16 induce apoptosis by targeting B-cell lymphoma 2 (BCL2) (20). miR-96 suppresses tumorigenesis by targeting KRAS in pancreatic cancer (21). These studies suggest that identification of tumor suppressor miRNAs is important to understand the molecular mechanisms underlying cancer progression. Previous studies have demonstrated that miRNAs can interact with the mTOR pathway during tumorigenesis, such as by targeting RPS6KB1, an important mediator of mTOR signaling. For example, miR-195 suppresses prostate cancer by directly targeting RPS6KB1 (22), and miR-15 and miR-16 have been reported to be involved in cell cycle arrest by targeting RPS6KB1 in breast cancer (23). Furthermore, miR-223 and miR-128 have also been reported to inhibit cancer by directly targeting RPS6KB1 $(24,25)$.

In our previous studies, several novel candidate miRNAs regulating the physiology of cancer cells were identified via functional screenings of miRNAs (26-29). Following the screenings, the functional mechanisms of the tumor suppressor miRNAs, miR-5582-5p and miR-550a-3-5p (26,27), and 
the epithelial-to-mesenchymal transition (EMT)-promoting miRNAs, miR-5003-3p and miR-181b-3p were demonstrated $(28,29)$. In this study, miR-5191, one of the miRNAs selected from the screening of miRNAs regulating the growth of the CRC cell line HCT116 (26), was characterized, and it was demonstrated that miR-5191 functions as a tumor suppressor in CRC by directly targeting RPS6KB1.

\section{Materials and methods}

Cell culture and reagents. Human CRC cell lines HCT116, HT-29, HCT15 and DLD1, and the human colon fibroblast line CCD-18co were obtained from the American Type Culture Collection and cultured in RPMI medium (Corning, Inc.) supplemented with $10 \%$ fetal bovine serum (Corning, Inc.), penicillin $(100 \mathrm{U} / \mathrm{ml})$ and streptomycin $(10 \mu \mathrm{g} / \mathrm{ml}$; both Gibco; Thermo Fisher Scientific, Inc.) at $37^{\circ} \mathrm{C}$ in a humidified incubator containing $5 \% \mathrm{CO}_{2}$. Antibodies against RPS6KB1 (cat. no. 9202), poly(ADP-ribose) polymerase (PARP; cat. no. 9542), retinoblastoma protein 1 (RB1; cat. no. 9309), cyclin D1 (cat. no. 2978), mTOR (cat. no. 2983) and S6 (cat.no. 2217) were purchased from Cell Signaling Technology, Inc. Antibodies against vimentin (cat. no. A301-620A), NOTCH2 (cat. no. A302-083A) and BCL2-associated agonist of cell death (BAD; cat. no. A302-384A) were purchased from Bethyl Laboratories, Inc. Antibodies against phosphorylated RB1 (cat. no. sc-271930), cyclin-dependent kinase 4 (CDK4; cat. no. sc-749), BAX (cat. no. sc-493), BCL2 (cat. no. sc-492), BAD (cat. no. sc-943), cyclin E (cat. no. sc-481) and $\beta$-actin (cat. no. sc-47778) were purchased from Santa Cruz Biotechnology, Inc. Antibodies against E-cadherin (cat. no. 610181) and N-cadherin (cat. no. 610920) were purchased from BD Biosciences. Horseradish peroxidase (HRP)-conjugated anti-mouse IgG (cat. no. A90-116P) and anti-rabbit IgG (cat. no. A120-101P) secondary antibodies were purchased from Bethyl Laboratories, Inc. To examine the epigenetic regulation of miR-5191 expression, cells were treated with histone methylation inhibitor 5-aza-2'-deoxycytidine (Merck KGaA) at $50 \mu \mathrm{M}$ for $72 \mathrm{~h}$, histone deacetylase inhibitor trichostatin A (Sigma-Aldrich; Merck KGaA) at $500 \mathrm{nM}$ for $12 \mathrm{~h}$, or TGF- $\beta$ (Sigma-Aldrich; Merck KGaA) at $5 \mathrm{ng} / \mathrm{ml}$ for $48 \mathrm{~h}$.

Transfection with RNA oligonucleotides and expression vectors. miR-5191 mimic was synthesized by Genolution Pharmaceuticals, Inc. as RNA duplexes designed from the sequences (5'-AGGAUAGGAAGAAUGAAGUGCU-3') registered in the miRBase database 22.1 (http://www.mirbase. org) (30). RNA duplex containing the sequence 5'-CUUACG CUGAGUACUUCGAUU-3' was used as a control miRNA. pcDNA3 plasmid and the expression vector for RPS6KB1 containing an N-terminal Myc with a pcDNA backbone (cat. no. 26610) were purchased from Invitrogen and Addgene, Inc., respectively. Small interfering (si)RNA duplex oligonucleotide targeting RPS6KB1 (si-RPS6KB1; cat. no. 36165) and scrambled negative control siRNA (cat. no. 37007) were purchased from Santa Cruz Biotechnology, Inc. For functional analyses, HCT116 and HT-29 cells were transfected at 30\% confluency with miRNA mimic or siRNA at a final concentration of $20 \mathrm{nM}$, and expression vectors $(2 \mu \mathrm{g})$ using $\mathrm{G}$-fectin
(Genolution Pharmaceuticals, Inc.) according to the manufacturer's protocol.

Determination of cell growth and cell cycle analysis. HCT116 and HT-29 cells were seeded in 24-well plates (1x10 4 cells/well) and transfected with miRNAs. At 24, 48, 72 and $96 \mathrm{~h}$ after transfection, cell growth was determined by counting the number of cells excluding trypan blue. Cells were stained with $0.4 \%$ trypan blue solution (Thermo Fisher Scientific, Inc.) at room temperature for $10 \mathrm{~min}$ and placed on a hematocytometer. Non-stained live cells and violet-stained dead cells were counted using an Eclips-TS2 microscope (magnification, x200; Nikon Corporation) in four randomly selected fields.

For cell cycle analysis, cells were fixed in ice-cold $70 \%$ ethanol for $2 \mathrm{~h}$ and treated with RNase A $(20 \mu \mathrm{g} / \mathrm{ml})$. Then, the cells were stained with propidium iodide (PI; $50 \mu \mathrm{g} / \mathrm{ml}$ ) at room temperature for $30 \mathrm{~min}$, and cell cycle distribution was analyzed using a FACSCalibur ${ }^{\mathrm{TM}}$ flow cytometer (BD Biosciences) and BD CellQuest Pro software version 5.2.1 (BD Biosciences).

Soft agar colony formation assay. Transfected HCT116 and HT-29 cells were suspended in $0.35 \%$ low-melting agarose/growth media and seeded on the top of solidified $0.5 \%$ low-melting agarose/growth media in $60-\mathrm{mm}$ dishes (500 cells/dish). The dishes were incubated at $37^{\circ} \mathrm{C}$ for 2 weeks with addition of fresh growth media every week. Cells were fixed with $4 \%$ formaldehyde at room temperature for $10 \mathrm{~min}$ and stained with $0.005 \%$ crystal violet at room temperature for $30 \mathrm{~min}$, and the number of colonies was counted.

Apoptosis analysis. Cell apoptosis was evaluated via flow cytometry after Annexin-FITC/PI double staining using an Annexin V-FITC Apoptosis Detection Kit I (BD Biosciences) according to the manufacturer's protocols. Briefly, the cells seeded in 6-well plates $\left(2 \times 10^{5}\right.$ cells/well) were transfected with miR-5191 or control miRNA and cultured for $48 \mathrm{~h}$. The cells were then stained and analyzed using FACSCalibur ${ }^{\mathrm{TM}}$ flow cytometer (BD Biosciences) and BD CellQuest Pro software version 5.2.1 (BD Biosciences). The sum of early and late apoptotic cells was calculated to determine the apoptotic rate.

$R N A$ isolation and reverse transcription-quantitative PCR (RT-qPCR) analysis. Total RNA was isolated from cultured cells or frozen tumor tissues using TRIzol ${ }^{\circledR}$ reagent (Invitrogen; Thermo Fisher Scientific, Inc.) or an RNeasy Mini kit (Qiagen $\mathrm{GmbH}$ ), respectively, according to the manufacturers' protocols. To quantify mRNA expression, total RNA $(1 \mu \mathrm{g})$ was reverse transcribed into cDNA using an AMPIGENE ${ }^{\circledR}$ cDNA Synthesis kit (Enzo Biochem, Inc.). The reaction mixtures were incubated sequentially at $42^{\circ} \mathrm{C}$ for $30 \mathrm{~min}$ and at $85^{\circ} \mathrm{C}$ for $10 \mathrm{~min}$. qPCR for $\mathrm{mRNA}$ determination was conducted using AMPIGENE ${ }^{\circledR}$ qPCR Green Mix (Enzo Biochem, Inc.) and an iCycler real-time PCR detection system (Bio-Rad Laboratories, Inc.) according to the manufacturers' protocols. The qPCR reaction conditions were as follows: Denaturation at $95^{\circ} \mathrm{C}$ for $2 \mathrm{~min}$, and 40 cycles of $95^{\circ} \mathrm{C}$ for $5 \mathrm{sec}, 60^{\circ} \mathrm{C}$ for $30 \mathrm{sec}$ and $72^{\circ} \mathrm{C}$ for $30 \mathrm{sec} . \beta$-Actin was used as the endogenous control for mRNA determination. The sequences of the specific primers were as follows: RPS6KB1, forward, 5'-CGG 
GACGGCTTTTACCCAG-3' and reverse, 5'-TTTCTCACA ATGTTCCATGCCA-3'; NOTCH2, forward, 5'-CAACCG CAATGGAGGCTATG-3', and reverse, 5'-GCGAAGGCA CAATCATCAATGTT-3'; $\beta$-actin, forward, 5'-ACCGAGCGC GGCTACAG-3' and reverse, 5'-CTTAATGTCACGCACGAT TTCC-3'.

To quantify miRNA expression, total RNA $(1 \mu \mathrm{g})$ was reverse transcribed into cDNA using an Mir-X miRNA First-Strand kit (Clontech Laboratories, Inc.). The reaction mixtures were incubated sequentially at $37^{\circ} \mathrm{C}$ for $1 \mathrm{~h}$ and at $85^{\circ} \mathrm{C}$ for $5 \mathrm{~min}$. qPCR for miRNA quantification was performed using an Mir-X miRNA qRT-PCR SYBR kit (Clontech Laboratories, Inc.). The thermocycling reaction conditions were as follows: Denaturation at $95^{\circ} \mathrm{C}$ for $10 \mathrm{sec}$, and 42 cycles of $95^{\circ} \mathrm{C}$ for $5 \mathrm{sec}, 60^{\circ} \mathrm{C}$ for $20 \mathrm{sec}$ and $72^{\circ} \mathrm{C}$ for $30 \mathrm{sec}$. qPCR for miRNA quantification was performed using an Mir-X miRNA qRT-PCR SYBR kit (Clontech Laboratories, Inc.). The sequences of the specific primers for each miRNA were as follows: miR-5191, 5'-AGGATAGGAAGAATG AAGTGCT-3'; miR-15a-5p, 5'-TAGCAGCACATAATG GTTTGTG-3'; miR-128, 5'-TCACAGTGAACCGGTCTC TTT-3'; miR-195, 5'-TAGCAGCACAGAAATATTGGC-3'; and miR-223-3p, 5'-TGTCAGTTTGTCAAATACCCCA-3'. RNU6B primers provided as a component of the kit were used as an endogenous control.

The expression levels of mRNA and miRNA were calculated according to the $2^{-\Delta \Delta \mathrm{Cq}}$ method (31).

Western blotting. Cells were lysed by boiling in 1X SDS sample buffer (Elpis Biotech. Inc.) to harvest proteins. Protein concentrations were measured using a Bicinchoninic Acid Assay kit (Thermo Fisher Scientific, Inc.). Denatured proteins $(20 \mu \mathrm{g})$ were separated via 8-10\% SDS-PAGE, and transferred to nitrocellulose membranes. After the transfer, the membranes were blocked in 5\% skim milk in TBS-Tween 20 (TBST; $10 \mathrm{mM}$ Tris- $\mathrm{HCl}, \mathrm{pH} 8.0,150 \mathrm{mM} \mathrm{NaCl}, 0.05 \%$ Tween 20) at room temperature for $40 \mathrm{~min}$ and incubated with specific primary antibodies diluted to $1: 1,000$ in the blocking solution at room temperature for $2 \mathrm{~h}$ (for E-cadherin and $\mathrm{N}$-cadherin) or overnight at $4^{\circ} \mathrm{C}$ (for all other antibodies). The membranes were then washed 3 times with TBST and incubated with HRP-conjugated anti-mouse IgG or anti-rabbit IgG secondary antibodies diluted to 1:5,000 in the blocking solution at room temperature for $1 \mathrm{~h}$, followed by detection using an enhanced chemiluminescence system (Amersham; GE Healthcare Life Sciences). Band intensities were quantitated using ImageJ software version 1.51J8 (National Institutes of Health) and normalized to $\beta$-actin.

Sphere formation assay. For sphere culture, cells were incubated in DMEM/F12 serum-free medium (Invitrogen; Thermo Fisher Scientific, Inc.) supplemented with 2\% B-27 (Invitrogen; Thermo Fisher Scientific, Inc.), $20 \mathrm{ng} / \mathrm{ml}$ epidermal growth factor (EGF; R\&D Systems, Inc.) and $20 \mathrm{ng} / \mathrm{ml}$ basic fibroblast growth factor (R\&D Systems, Inc.) in 6-well ultra-low cluster plates (Corning, Inc.). When the diameters of formed spheres reached $\sim 50 \mu \mathrm{m}$, spheroid cells were transfected with miR-5191 or control miRNA at a final concentration of $100 \mathrm{nM}$, si-RPS6KB1 or control siRNA at a final concentration of $100 \mathrm{nM}$, or RPS6KB1 expression vector or empty
pcDNA3 plasmid $(2 \mu \mathrm{g})$ using Viromer-Blue (Lipocalyx $\mathrm{GmbH}$ ) according to the manufacturer's protocol. At 4 days after transfection, the images of spheres were captured with an Eclips-TS2 microscope (magnification, x200), and the number and diameter of spheres were measured in four randomly selected fields.

Organoid culture. Human CRC tissue resected from a 59-year-old female patient with CRC in March 2018 was obtained from the Korea Cancer Center Hospital in Korea Institute of Radiological and Medical Sciences (KIRAMS). Informed consent was obtained from patients, and the study was approved by the institutional review board (IRB) of KIRAMS (IRB no. 2017-07-001). Tumor cells were isolated as described by Sato et al (32) and were suspended in Matrigel (Sigma-Aldrich; Merck KGaA) and solidified in multi-well plates. Well containing solidified Matrigel were filled with organoid culture medium (1X B-27 supplement, $1.25 \mathrm{mM}$ n-acetyl cysteine, $50 \mathrm{ng} / \mathrm{ml}$ EGF, $50 \mathrm{ng} / \mathrm{ml}$ noggin, $10 \mathrm{nM}$ gastrin, $500 \mathrm{nM} \mathrm{A83-01} \mathrm{and} 100 \mathrm{mg} / \mathrm{ml}$ primocin) and incubated at $37^{\circ} \mathrm{C}$ in a humidified incubator containing $5 \% \mathrm{CO}_{2}$. Organoids were trypsinized in TripLE (Invitrogen; Thermo Fisher Scientific, Inc.) at $37^{\circ} \mathrm{C}$ for $5 \mathrm{~min}$ to obtain single cells. The cells were plated in 48 -well plates at $70 \%$ confluency and transfected with miR-5191 or control miRNA at a final concentration of $100 \mathrm{nM}$ using Lipofectamine ${ }^{\circledR}$ 2000 (Invitrogen; Thermo Fisher Scientific, Inc.) according to the manufacturer's protocol. Then the cells were reseeded in Matrigel. After 7 days, organoid viability was determined by MTT assay as described previously (33). In brief, MTT solution was added to the organoid culture at a final concentration of $500 \mu \mathrm{g} / \mathrm{ml}$. After incubation for $1 \mathrm{~h}, 20 \mu \mathrm{l}$ of $2 \%$ SDS solution was added to solubilize the Matrigel and $100 \mu \mathrm{l}$ of DMSO was added to solubilize the reduced MTT, and the optical density was measured at $562 \mathrm{~nm}$. The images of organoids were acquired using an EVOS FL Cell Imaging System (Thermo Fisher Scientific, Inc), and the number and size of organoids were analyzed by ImageJ software version $1.51 \mathrm{~J} 8$ in four randomly selected fields.

Invasion assay. For the invasion assay, transfected cells suspended in serum-free RPMI medium were reseeded onto Matrigel-coated filters in the upper chamber $\left(5 \times 10^{4}\right.$ cells/well $)$ of Boyden chambers (Corning, Inc.). The lower chambers were filled with $800 \mu \mathrm{l}$ of complete medium. After incubation for $48 \mathrm{~h}$ for HCT116 cells and $60 \mathrm{~h}$ for HT-29 cells, the invaded cells in the lower surface of the filters were fixed for $5 \mathrm{~min}$ in solution $\mathrm{A}$, and stained for 5 min in solution B and solution C each, then washed 3 times for 1 min in distilled water (all at room temperature) using a Diff-Quick stain kit (Polysciences, Inc.). The stained cells were counted using an Eclips-TS2 microscope (magnification, $\mathrm{x} 200$ ) in four randomly selected fields.

Selection of the putative targets of miR-5191. Putative binding sites for miR-5191 were predicted using miRNA target prediction programs: DIANA-MICROT (http://www.diana.imis. athena-innovation.gr) (34); TargetScan (http://www.targetscan. org) (35); and miRDB (http://www.mirdb.org) (36). The genes predicted by all three different algorithms to contain 
the putative binding sites of miR-5191 in their 3'UTRs were selected as targets of miR-5191.

Reporter assay. To prepare the reporter constructs, a DNA fragment of the human RPS6KB1 3'UTR containing the putative miR-5191 binding site was cloned into a pGL3UC vector (kindly provided by V.N. Kim, Seoul National University, Republic of Korea) (37). The 3'UTR sequence of the RPS6KB1 gene containing the putative binding sites of miR-5191 was amplified using GenomicsOne 5X PCR Premix (GenomicsOne Co., Ltd.) according to the manufacturer's protocol. PCR reaction conditions were: Denaturation at $94^{\circ} \mathrm{C}$ for $2 \mathrm{~min}$, and 35 cycles of $94^{\circ} \mathrm{C}$ for $30 \mathrm{sec}, 54^{\circ} \mathrm{C}$ for $30 \mathrm{sec}$ and $72^{\circ} \mathrm{C}$ for $30 \mathrm{sec}$. The nucleotide sequences of primers for the amplification of the RPS6KB1 3'UTR were forward, 5'-CCTCTAGAG CAAGCTGGACAAAC-3' and reverse, 5'-CCGAATTCGGTG TTACCCTCATAG-3'. HCT116 cells were seeded in 24-well plates $\left(5 \times 10^{4}\right.$ cells/well) and co-transfected with the reporter plasmid/empty pGL3UC (100 ng), pRL-CMV-Renilla plasmid (2 ng; Promega Corporation) and miR-5191 mimic/control miRNA (20 nM) using Lipofectamine ${ }^{\circledR} 2000$ according to the manufacturer's protocol. After $48 \mathrm{~h}$ of transfection, luciferase activity was measured using a Dual Luciferase Reporter Assay system (Promega Corporation) according to the manufacturer's protocol. Firefly luciferase activity was normalized to Renilla luciferase activity. Experiments were performed in triplicate.

Patient specimens. Twenty-two pairs of CRC and adjacent normal colon tissues were obtained from the KIRAMS Radiation Tissue Biobank (patient information was not available for these tissue samples). Written informed consent was obtained from each patient before the collection of specimens, and the use of CRC patient specimens was approved by the IRB of KIRAMS (IRB no. K-1610-002-003). The study was conducted in accordance with the Declaration of Helsinki.

Tumor xenograft experiments. The protocol for animal experiments was reviewed and approved by the Institutional Animal Care and Use Committee of KIRAMS (permit no. 2017-0056). A total of 16 female BALB/c nu/nu mice (4-week-old females weighing 18-20 g) were purchased from Orientbio Inc. and maintained under specific pathogen-free conditions at $23 \pm 1^{\circ} \mathrm{C}$ with $50 \pm 10 \%$ humidity-controlled conditions under a 12:12-h light/dark cycle. Food and water were provided ad libitum. HCT116 xenografts were established by subcutaneous injection of $5 \times 10^{6}$ cells into the right hind leg of 5-week-old mice. When the average tumor size reached $150 \mathrm{~mm}^{3}$, intratumoral injection of miRNA was started and repeated once, with a 3-day interval. Control miRNA or miR-5191 (10 $\mu \mathrm{g})$ was complexed with $1.2 \mu \mathrm{l}$ of in vivo-jetPEI (Polyplus-transfection $\mathrm{SA}$ ) in a volume of $50 \mu \mathrm{l}$ per injection according to the manufacturer's protocol ( $n=6 /$ group). Tumor size was measured twice a week, and the tumor volume was calculated using the equation: Tumor volume $(\mathrm{V})=(\text { small diameter })^{2} \mathrm{x}$ (large diameter) $\mathrm{x}(\pi / 6)$. Mice were sacrificed by $\mathrm{CO}_{2}$ euthanasia before the tumor volume reached $1,800 \mathrm{~mm}^{3}$, with a fill rate of $10-30 \%$ of the chamber volume/min. After 3 min of $\mathrm{CO}_{2}$ injection into the chamber, mice were checked for a lack of respiration and faded eye color to confirm euthanasia.
Immunohistochemistry (IHC) of xenograft tumor tissues was performed using a Ready-to-use IHC/ICC kit (BioVision, Inc.) according to the manufacturer's protocol. Briefly, the mouse tumor tissues were fixed with $4 \%$ formaldehyde at room temperature for $24 \mathrm{~h}$. Paraffin-embedded tissues were cut into $5 \mu \mathrm{m}$-thick sections, deparaffinized, rehydrated and microwaved in citrate buffer (cat. no. ab93678; Abcam) for antigen retrieval. The slides were incubated in $3 \% \mathrm{H}_{2} \mathrm{O}_{2}$ at room temperature for $30 \mathrm{~min}$ to quench endogenous peroxidase activity, and then blocked in blocking buffer (BioVision, Inc.) at room temperature for $15 \mathrm{~min}$, followed by incubation with anti-RPS6KB1 (1:100), anti-cyclin D1 (1:100) or anti-BAD (1:100) antibodies at room temperature for $30 \mathrm{~min}$. After incubation with HRP-anti-mouse or -rabbit IgG polymer at room temperature for $20 \mathrm{~min}$ and washing with PBS, the tissue sections were treated with 3,3'-diaminobenzidine at room temperature for $10 \mathrm{~min}$, followed by counterstaining with hematoxylin at room temperature for $1 \mathrm{~min}$. Images were captured with an Eclips-TS2 microscope (magnification, x200).

Statistical analysis. All data are presented as the mean \pm SEM. All statistical analyses were performed using SPSS 17.0 (SPSS, Inc.) and GraphPad Prism software 5 (GraphPad Software, Inc.). Student's t-test was used to compare the difference between two groups, and one-way ANOVA with post hoc Tukey's test was performed to compare the differences among more than two groups. Repeated-measures ANOVA was used to analyze tumor volume over time in the xenograft study. $\mathrm{P}<0.05$ were considered to indicate a statistically significant difference. The correlation between the expression levels of RPS6KB1 and miR-5191 was determined by Spearman analysis.

\section{Results}

miR-5191 induces apoptosis and cell cycle arrest. Several novel candidate miRNAs were previously identified following a functional screening of proliferation inhibition in HCT116 cells (26); miR-5191 was one of the selected miRNAs. To determine the functional roles of miR-5191 in tumor initiation and progression, HCT116 and HT-29 cells were transfected with miR-5191 or control miRNA and the effects were assessed. Transfection efficacy was confirmed by RT-qPCR analysis, revealing that miR-5191 levels were significantly increased after transfection with miR-5191 (Fig. 1A). Viable cell counting after transfection with miR-5191 revealed that cell proliferation was inhibited by miR-5191 in both CRC cell lines (Fig. 1B). Colony formation in soft agar was also inhibited by miR-5191 transfection (Fig. 1C). Furthermore, transfection with miR-5191 resulted in an increased $\mathrm{G}_{1}$-phase cell population and a decreased $S$-phase cell population, indicating cell cycle arrest at the $\mathrm{G}_{1} / \mathrm{S}$-phase boundary induced by miR-5191 (Fig. 1D). Accordingly, RB phosphorylation, and the expression levels of the cell cycle-associated proteins CDK4, cyclin D and cyclin E, were reduced after miR-5191 transfection (Fig. 1E). In addition, apoptosis was significantly induced in HCT116 and HT-29 cells after miR-5191 transfection (Fig. 1F). miR-5191-induced apoptosis was accompanied by PARP cleavage, increased expression of proapoptotic BAX and decreased expression of antiapoptotic BCL2 (Fig. 1G). 
A

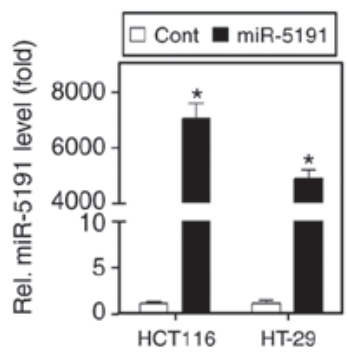

E
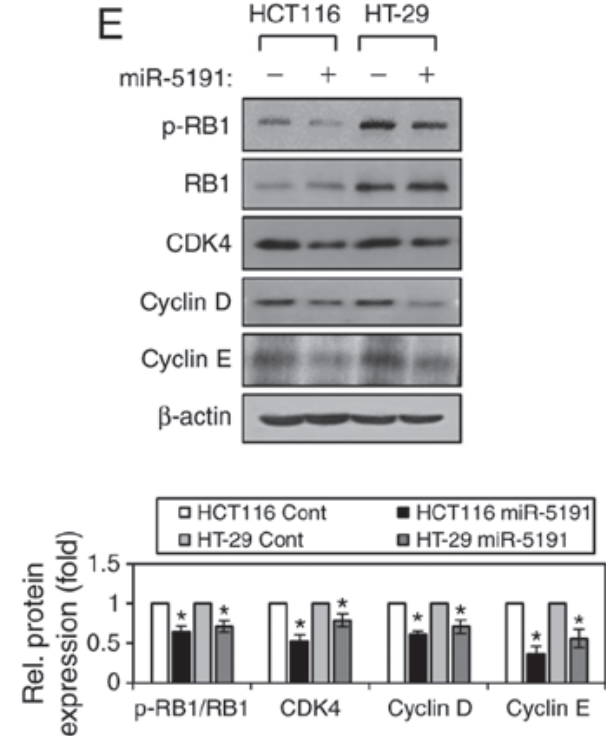

B

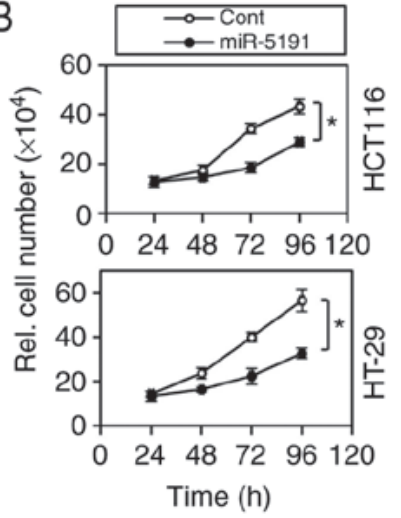

$\mathrm{F}$
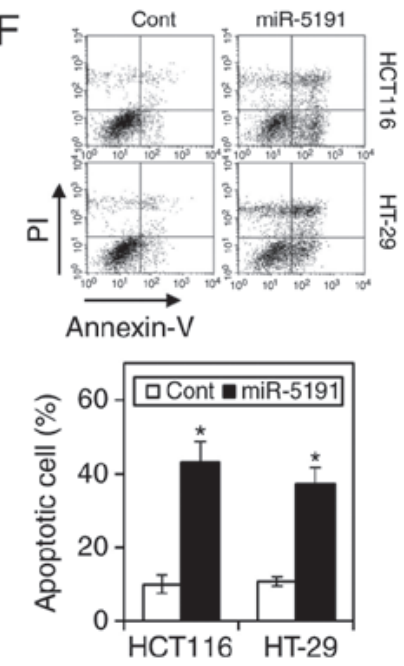

D

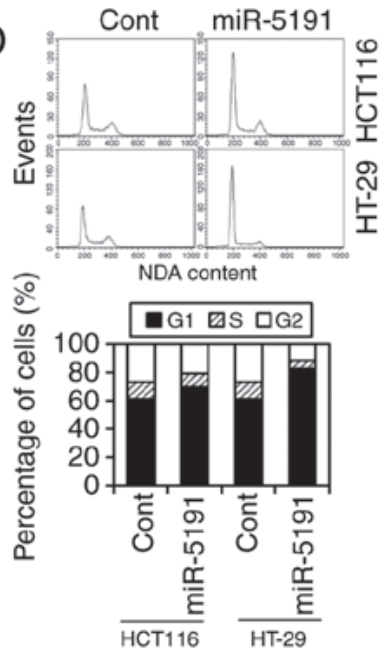

G

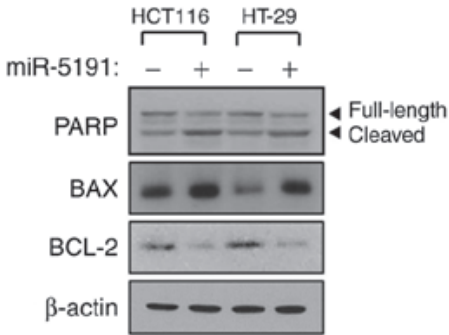

Figure 1. miR-5191 induces apoptosis and cell cycle arrest. (A) Determination of miR-5191 expression after transfection with miR-5191. Total RNA was prepared from the transfected cells and miR-5191 levels were analyzed by reverse transcription-quantitative PCR analysis. $R N U 6 B$ was used as a reference gene. P-values were calculated by Student's t-test. Data are presented as the mean \pm SEM. ${ }^{*}<<0.05$ vs. Cont ( $\mathrm{n}=3$ ). (B) Antiproliferative effects of miR-5191. HCT116 and HT-29 cells were transfected with miR-5191 or control miRNA in 6-well dishes, and cell numbers were counted at the indicated time. P-values were calculated by Student's t-test. Data are presented as the mean \pm SEM. ${ }^{*} \mathrm{P}<0.05(\mathrm{n}=3)$. (C) Inhibition of colony formation by miR-5191. P-values were calculated by Student's t-test. Data are presented as the mean \pm SEM. ${ }^{*} \mathrm{P}<0.05$ vs. Cont (n=3). (D) miR-5191 induces cell cycle arrest. HCT116 and HT-29 cells transfected with miR-5191 or control miRNA were analyzed by flow cytometry after PI staining. Data shown are representative of three independent experiments. (E) Downregulation of G1/S phase cell cycle-associated proteins by miR-5191. The cell lysates of HCT116 and HT-29 cells were prepared 3 days after transfection with miR-5191 or control miRNA, and subjected to western blot analysis. P-values were calculated by Student's t-test. Data are presented as the mean \pm SEM. ${ }^{*} \mathrm{P}<0.05$ vs. Cont $(\mathrm{n}=3)$. (F) miR-5191 induces apoptosis. Flow cytometric analyses were carried out 3 days after transfection of HCT116 and HT-29 cells with miR-5191 or control miRNA after staining with Annexin V-FITC/PI. Data shown are representative of three independent experiments. P-values were calculated by Student's t-test. Data are presented as the mean \pm SEM. ${ }^{*} \mathrm{P}<0.05$ vs. Cont ( $\mathrm{n}=3$ ). (G) Altered expression of apoptosis-related proteins after miR-5191 transfection. P-values were calculated by Student's t-test. Data are presented as the mean \pm SEM. ${ }^{*} \mathrm{P}<0.05 \mathrm{vs}$. Cont ( $=3$ ). CDK4, cyclin-dependent kinase 4; Cont, control miRNA; miR/miRNA, microRNA; p-, phosphorylated; PARP, poly(ADP-ribose) polymerase; PI, propidium iodide; $\mathrm{RB} 1$, retinoblastoma protein 1 .

miR-5191 suppresses the sphere formation, organoid growth and invasiveness of CRC cells. Next, the effects of miR-5191 on various tumorigenesis-associated characteristics of CRC cells were assessed. First, whether miR-5191 affected the maintenance of the cancer stem cell (CSC)-like phenotype of CRC cells was evaluated. Sphere culture under a serum-free condition has been used successfully to enrich CSC-like cells (38) and thus can be used to determine the self-renewal capacity of CSCs. The tumorsphere formation ability of HCT116 and HT-29 cells in stem cell medium was assessed 4 days after transfection with miR-5191 or control miRNA (Fig. 2A). The number and size of tumorspheres were significantly decreased by miR-5191 transfection (Fig. 2A). Recently, organoid model systems employing 3D cultures in Matrigel-containing serum-free medium have been increasingly used to determine the biological characteristics of various CSCs (39-41). Patient-derived tumor organoids were used to investigate the function of miR-5191 on tumor organoid growth. miR-5191-transfected cells formed smaller tumor organoids compared with control-transfected cells (Fig. 2B). Suppression of tumor organoid growth by miR-5191 was also determined by evaluating cell viability using an MTT assay (Fig. 2B). Aggressive and metastatic cancer cells are characterized by high invasiveness, which is closely associated with EMT (42). Transwell assays with Matrigel were used to determine the invasive potential of cancer cells. Transfection with miR-5191 significantly decreased the invasive abilities of HCT116 and HT-29 cells (Fig. 2C). In accordance, miR-5191 transfection 


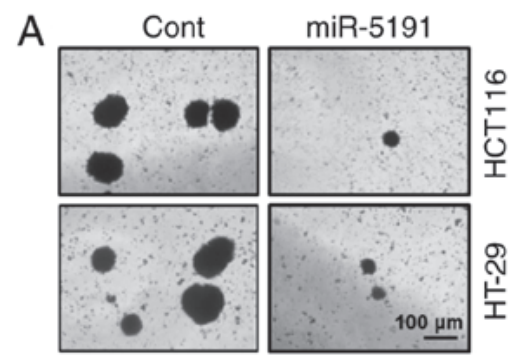

B

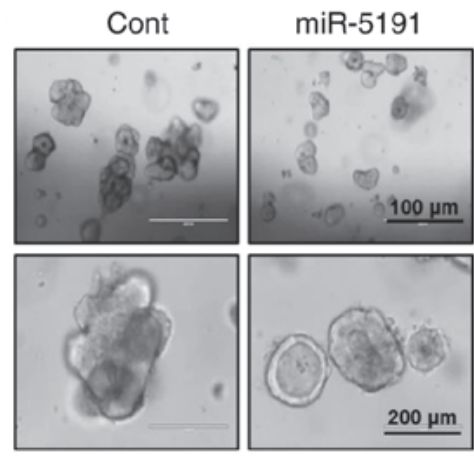

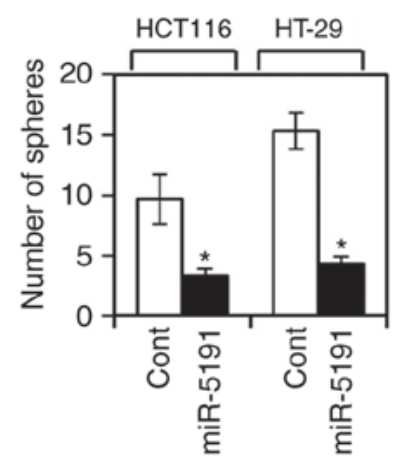

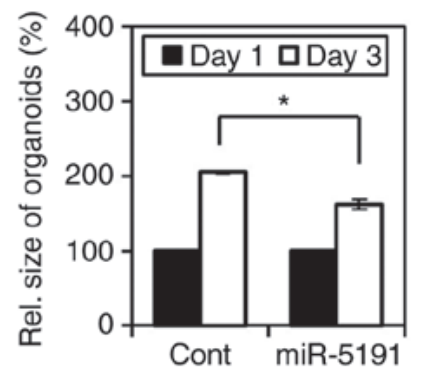

C

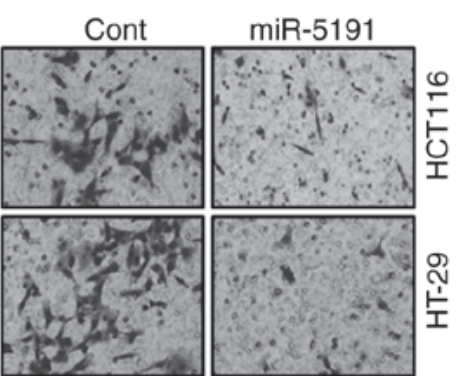

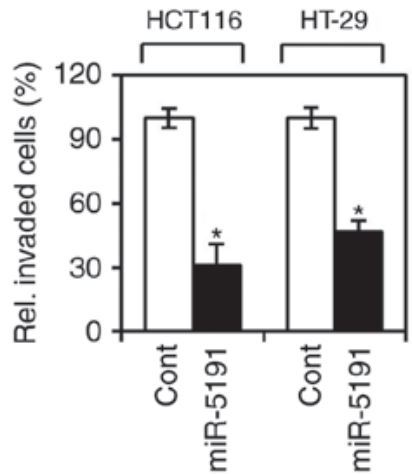
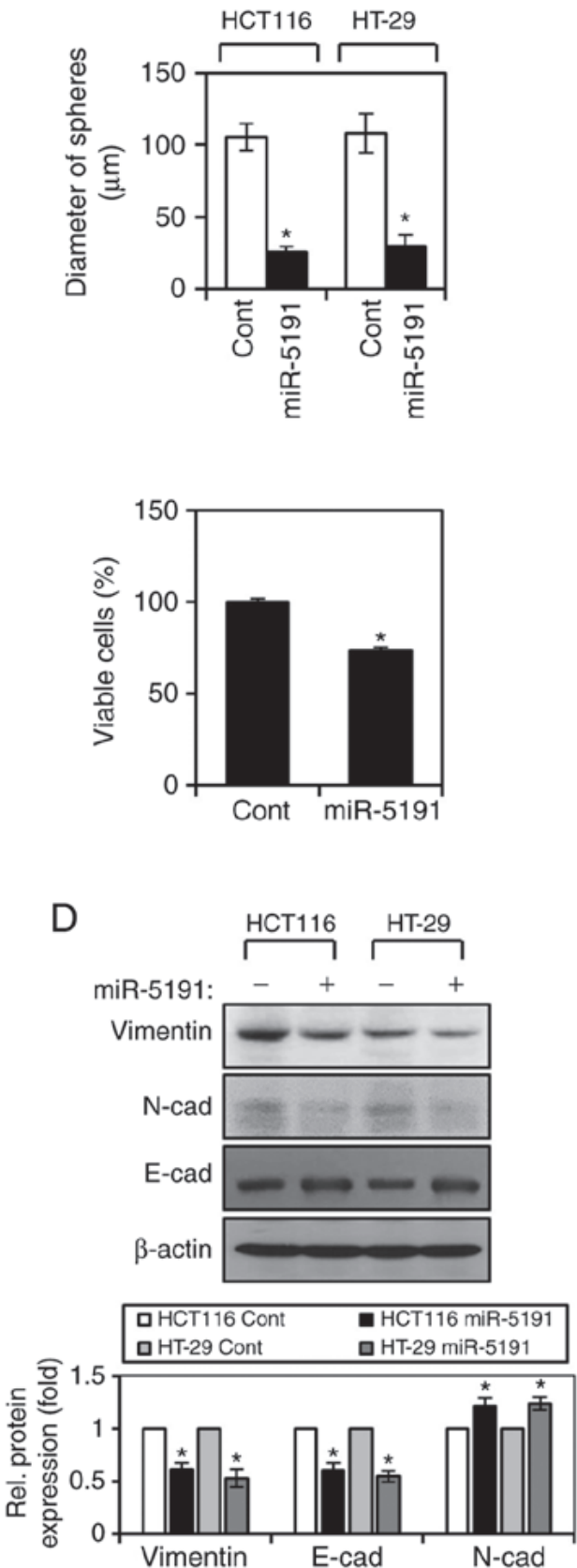

Figure 2. miR-5191 suppresses the sphere formation, organoid growth and invasion of CRC cells. (A) miR-5191 inhibits sphere formation. HCT116 and HT-29 cells were sphere-cultured and transfected with miR-5191 or control miRNA. Representative microscopic images and presented, and the number and diameters of the grown spheres observed 4 days after transfection were compared. P-values were calculated by Student's t-test. Data are presented as the mean \pm SEM. "P<0.05 vs. Cont ( $\mathrm{n}=3$ ). (B) miR-5191 inhibits organoid growth. Patient-derived CRC cells were transfected with miR-5191 or control miRNA and cultured in organoid growth conditions for 7 days. Representative microscopic images of grown organoids are shown. The diameters of organoids at days 1 and 3 after organoid culture were determined with a microscope, and viable cells in organoids were determined by an MTT assay. P-values were calculated by Student's t-test. Data are presented as the mean \pm SEM. ${ }^{~} \mathrm{P}<0.05(\mathrm{n}=3)$. (C) miR-5191 inhibits the invasion of CRC cells. HCT116 and HT-29 cells transfected with miR-5191 or control miRNA were allowed to migrate through Matrigel-coated filters. The number of invaded cells per Transwell was determined. P-values were calculated by Student's t-test. Data are presented as the mean \pm SEM. ${ }^{*} \mathrm{P}<0.05$ vs. Cont $(\mathrm{n}=3)$. Magnification, $\mathrm{x} 200$. (D) miR-5191 suppresses the expression of epithelial-to-mesenchymal transition marker proteins. The cell lysates of HCT116 and HT-29 cells were prepared 3 days after transfection with miR-5191 or control miRNA and subjected to western blot analysis. P-values were calculated by Student's t-test. Data are presented as the mean \pm SEM. "P<0.05 vs. Cont ( $\mathrm{n}=3)$. Cad, cadherin; Cont, control miRNA; CRC, colorectal cancer; miR/miRNA, microRNA.

inhibited the expression of the mesenchymal markers vimentin and $\mathrm{N}$-cadherin, and enhanced the expression of the epithelial marker E-cadherin, indicating suppression of EMT by miR-5191 (Fig. 2D).

miR-5191 directly targets RPS6KB1. A number of candidate proteins were predicted as targets of miR-5191 by the miRNA target prediction algorithms miRDB, Diana, and TargetScan (Fig. 3A). Among the nine proteins commonly predicted by the three algorithms, two proteins, RPS6KB1 and NOTCH2, which are well-known oncogenic molecules involved in various types of tumorigenesis $(43,44)$, were selected for validation as targets of miR-5191. First, the protein and mRNA expression levels of the two target candidates were 

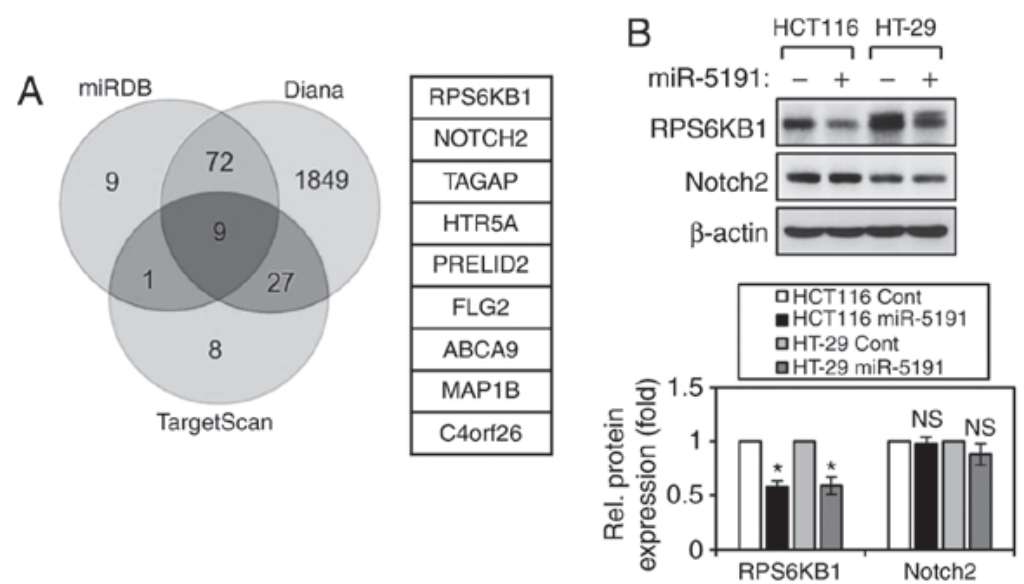

D

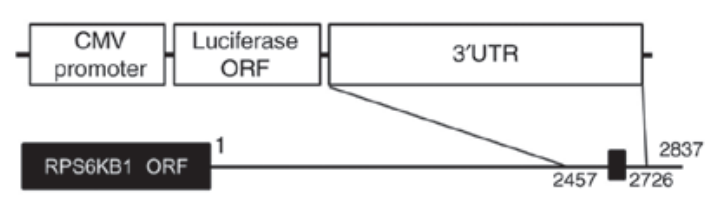

RPS6KB1 3'UTR 5'- GCUCUUUA AACUAUUGU UUC- UCCUAUCCC - 3 ' II IIII III IIIIIIII

miR-5191 3'- UCGUGAAGU AAGA AGGAUAGGA - 5
E

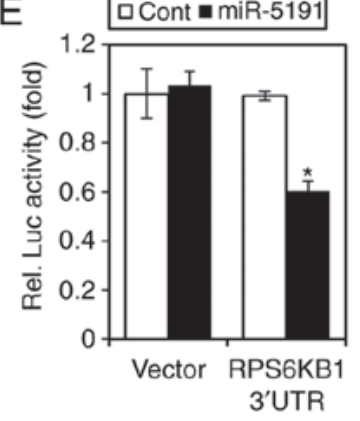

C
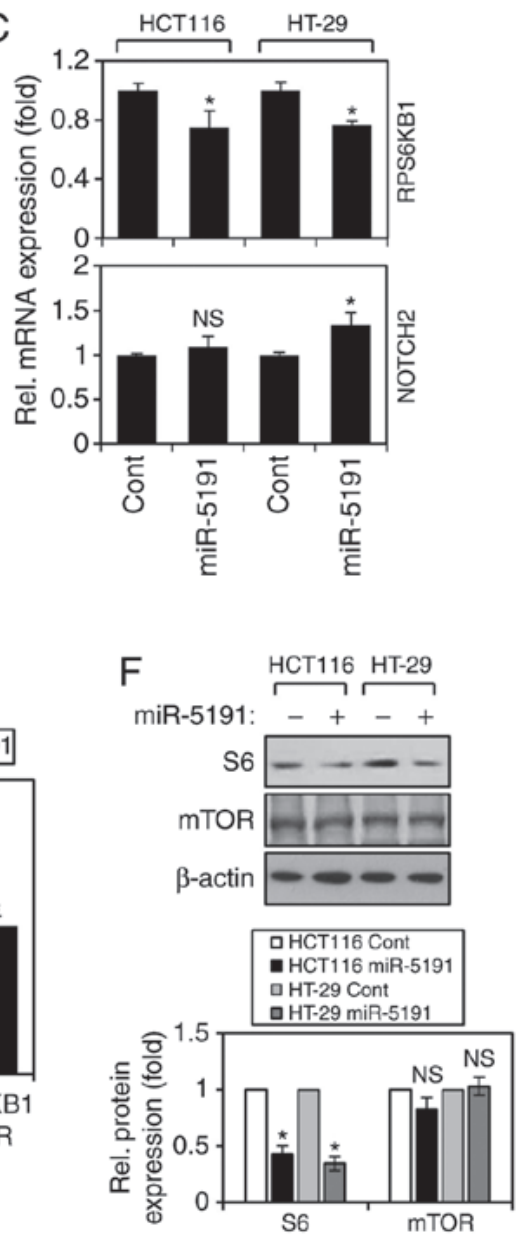

Figure 3. miR-5191 directly targets RPS6KB1. (A) Venn diagram showing the numbers of the putative miR-5191 targets predicted by miRNA target prediction algorithms. (B) miR-5191 suppresses the expression of RPS6KB1. HCT116 and HT-29 cells were transfected with miR-5191, and cell lysates were prepared $48 \mathrm{~h}$ after transfection for western blot analysis. P-values were calculated by Student's t-test. Data are presented as the mean \pm SEM. "P<0.05 vs. Cont ( $\mathrm{n}=3$ ). (C) miR-5191 downregulates the mRNA expression of RPS6KB1. Total RNA was prepared from the transfected cells, and the mRNA levels of RPS6KB1 and NOTCH2 were analyzed via reverse transcription-quantitative PCR analysis. B-Actin was used as a reference gene. P-values were calculated by Student's $\mathrm{t}$-test. Data are presented as the mean \pm SEM. " $\mathrm{P}<0.05$ vs. Cont ( $\mathrm{n}=3$ ). (D) Construction of reporter containing the predicted miR-5191 target sequences in the 3'UTR of RPS6KB1. (E) Reporter assay showing the direct targeting of 3'UTR of RPS6KB1 by miR-5191. HCT116 cells were co-transfected with a combination of reporter and reference plasmids, and miRNA, and luciferase activity was measured $48 \mathrm{~h}$ after transfection. Firefly luciferase activity was normalized to Renilla luciferase activity. P-values were calculated by Student's t-test. Data are presented as the mean \pm SEM. ${ }^{*} \mathrm{P}<0.05$ vs. Cont $(\mathrm{n}=3)$. (F) miR-5191 suppresses the expression of S6. P-values were calculated by Student's t-test. Data are presented as the mean \pm SEM. "P<0.05 vs. Cont ( $\mathrm{n}=3$ ). Cont, control miRNA; miR/miRNA, microRNA; n.s., not significant; RPS6KB1, ribosomal protein S6 kinase $\beta 1$; UTR, untranslated region.

evaluated after transfection of miR-5191 into HCT116 and HT-29 cells. In both cell lines, the protein expression levels of RPS6KB1 were significantly reduced when the cells were transfected with miR-5191, whereas those of NOTCH2 were not altered (Fig. 3B). Consistent with this observation, the mRNA levels of RPS6KB1, but not those of NOTCH2, were also decreased upon transfection with miR-5191 (Fig. 3C). Based on these results, RPS6KB1 was further investigated to evaluate whether it is a direct target of miR-5191 by means of a reporter assay. One putative miR-5191-binding site that is complementary to the seed region of miR-5191 was identified in the 3'UTR of RPS6KB1. The putative miR-5191-binding sequence was cloned into the modified pGL3 reporter vector pGL3UC, as presented in Fig. 3D. Luciferase activity was measured $48 \mathrm{~h}$ after co-transfection of the reporter construct with either control miRNA or miR-5191 into HCT116 cells. Co-transfection with miR-5191 significantly reduced the relative luciferase activity of the RPS6KB1 3'UTR reporter
(Fig. 3E), indicating that RPS6KB1 is a direct target of miR-5191. As RPS6KB1 is a key effector molecule of mTOR signaling, the effects of miR-5191 on the expression of mTOR and S6 were also examined. miR-5191 transfection reduced the expression of S6, a downstream target of RPS6KB1, but did not alter the expression levels of mTOR, an upstream effector of RPS6KB1 (Fig. 3F).

miR-5191-induced tumor suppression occurs through the downregulation of RPS6KB1. To validate the importance of directly targeting RPS6KB1 for the tumor-suppressive function of miR-5191, whether the restoration of RPS6KB1 expression could suppress the effects of miR-5191 transfection was then investigated. Ectopic expression of RPS6KB1, from a myc-RPS6KB1 expression vector, co-transfected with miR-5191, prevented the $\mathrm{G}_{1}$-phase population increase induced by miR-5191 (Fig. 4A and B). Moreover, ectopic expression of RPS6KB1 efficiently suppressed miR-5191-induced apoptosis 
A

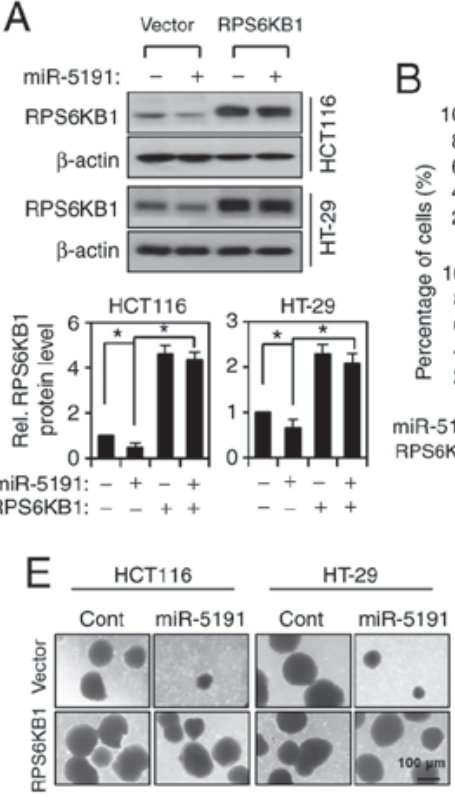

C

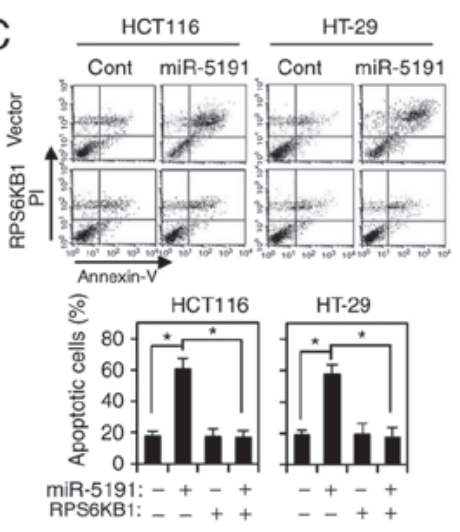

$\mathrm{D}$

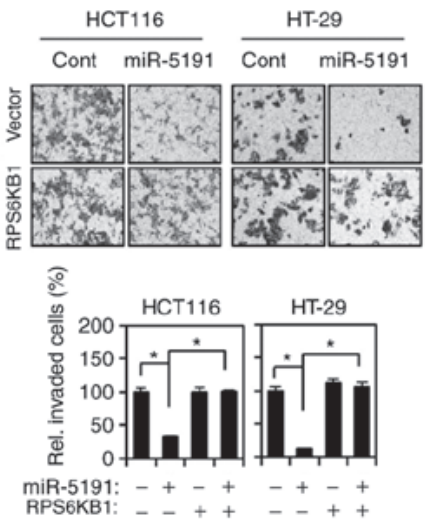

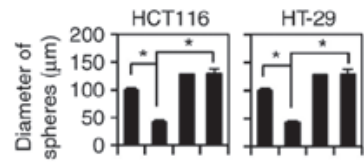

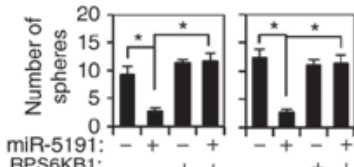

$\mathrm{F}$ sing

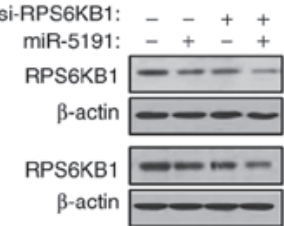

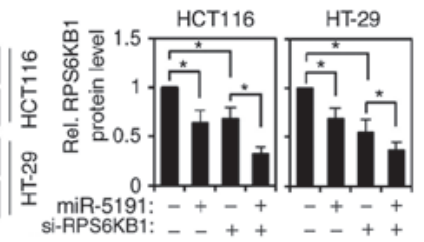

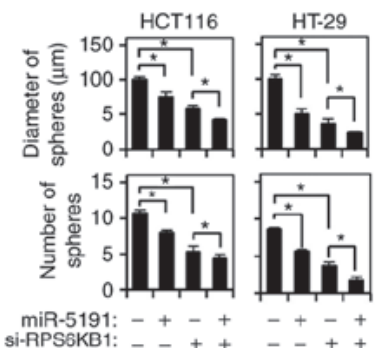

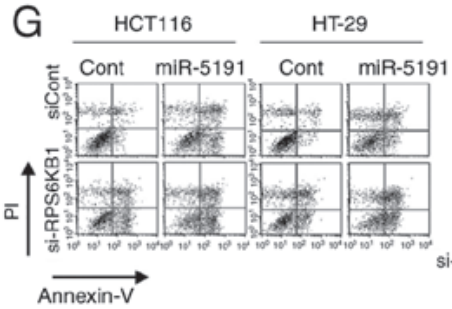

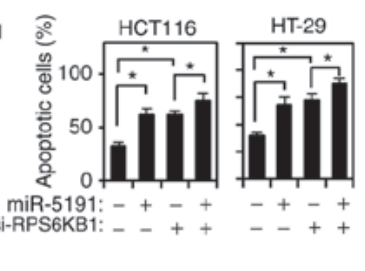

$\mathrm{H}$

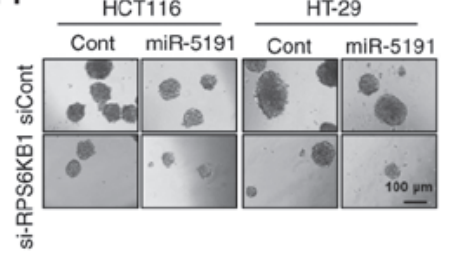

Figure 4. miR-5191-induced tumor suppression occurs via the downregulation of RPS6KB1. (A) Restoration of RPS6KB1 protein levels after ectopic expression of myc-RPS6KB1. HCT116 and HT-29 cells were transfected with a combination of miR-5191 $(20 \mathrm{nM})$ and RPS6KB1 expression vector ( $2 \mu \mathrm{g})$. RPS6KB1 expression levels are shown below. P-values were calculated by ANOVA with Tukey's post hoc test. Data are presented as the mean \pm SEM. "P<0.05 ( $n=3$ ). (B) Restoration of RPS6KB1 expression reduces miR-5191-induced cell cycle arrest. Data shown are representative of three independent experiments. (C) Ectopic expression of RPS6KB1 suppresses miR-5191-induced apoptosis. Flow cytometric analysis was performed $72 \mathrm{~h}$ after transfection with miR-5191 and RPS6KB1 expression vector. Data shown are representative of three independent experiments. P-values were calculated by ANOVA with Tukey's post hoc test. Data are presented as the mean \pm SEM. ${ }^{*} \mathrm{P}<0.05(\mathrm{n}=3)$. (D) Ectopic expression of RPS6KB1 rescues miR-5191-mediated inhibition of colorectal cancer cell invasion. P-values were calculated by ANOVA with Tukey's post hoc test. Data are presented as the mean \pm SEM. ${ }^{*} \mathrm{P}<0.05$ ( $\mathrm{n}=3$ ). Magnification, $\mathrm{x} 200$. (E) Ectopic expression of RPS6KB1 rescues miR-5191-mediated inhibition of tumor sphere growth. Total number and diameters of spheres were observed with a microscope 4 days after transfection. P-values were calculated by ANOVA with Tukey's post hoc test. Data are presented as the mean \pm SEM. "P $<0.05$ ( $n=3$ ). (F) Determination of RPS6KB1 expression levels after transfection with miR-5191 or si-RPS6KB1. HCT116 and HT-29 cells were transfected and cell lysates were prepared $48 \mathrm{~h}$ after transfection. RPS6KB1 expression levels are shown to the right. P-values were calculated by ANOVA with Tukey's post hoc test. Data are presented as the mean \pm SEM. ${ }^{*} \mathrm{P}<0.05(\mathrm{n}=3)$. (G) Determination of miR-5191-induced apoptosis in RPS6KB1-depleted background. Flow cytometric analysis was conducted $72 \mathrm{~h}$ after transfection with an indicated combination of miR-5191 and si-RPS6KB1. Data shown are representative of three independent experiments. P-values were calculated by ANOVA with Tukey's post hoc test. Data are presented as the mean \pm SEM. "P<0.05 ( $n=3)$. (H) Determination of the inhibition of tumor sphere growth by miR-5191 in RPS6KB1-depleted background. Total number and diameters of spheres were observed with a microscope 4 days after transfection. P-values were calculated by ANOVA with Tukey's post hoc test. Data are presented as the mean \pm SEM. ${ }^{*} \mathrm{P}<0.05$ ( $\mathrm{n}=3$ ). Cont, control mi/siRNA; miR/miRNA, microRNA; PI, propidium iodide; RPS6KB1, ribosomal protein S6 kinase $\beta 1$; si, small interfering (RNA).

(Fig. 4C). Ectopic expression of RPS6KB1 also attenuated the inhibition of cell invasion induced by miR-5191 transfection (Fig. 4D). Then, the effect of RPS6KB1 expression on the sphere growth-inhibiting activity of miR-5191 was examined. The size and number of spheres, which were reduced by miR-5191 transfection, were restored to those of control cultures by co-expression of the RPS6KB1 protein (Fig. 4E). To further evaluate the importance of RPS6KB1-trageting, the effects of enforced downregulation of RPS6KB1 expression using si-RPS6KB1. RPS6KB1 expression was downregulated similarly by transfection with siRNA or miR-5191, and further downregulated by the combined transfection of si-RPS6KB1 and miR-5191 (Fig. 4F). Knocking down RPS6KB1 expression significantly induced apoptosis and inhibited sphere growth in the same manner as miR-5191 (Fig. 4G and H). Co-transfection with miR-5191 further augmented the induction of apoptosis and inhibition of sphere growth, suggesting other targets may serve additional roles in the tumor-suppressive function of miR-5191.

miR-5191 and RPS6KB1 expression levels are inversely correlated in CRC tissues. The expression levels of miR-5191 and other miRNAs known to target RPS6KB1 (22-25) were determined in CRC and normal cell lines via RT-qPCR analysis . 

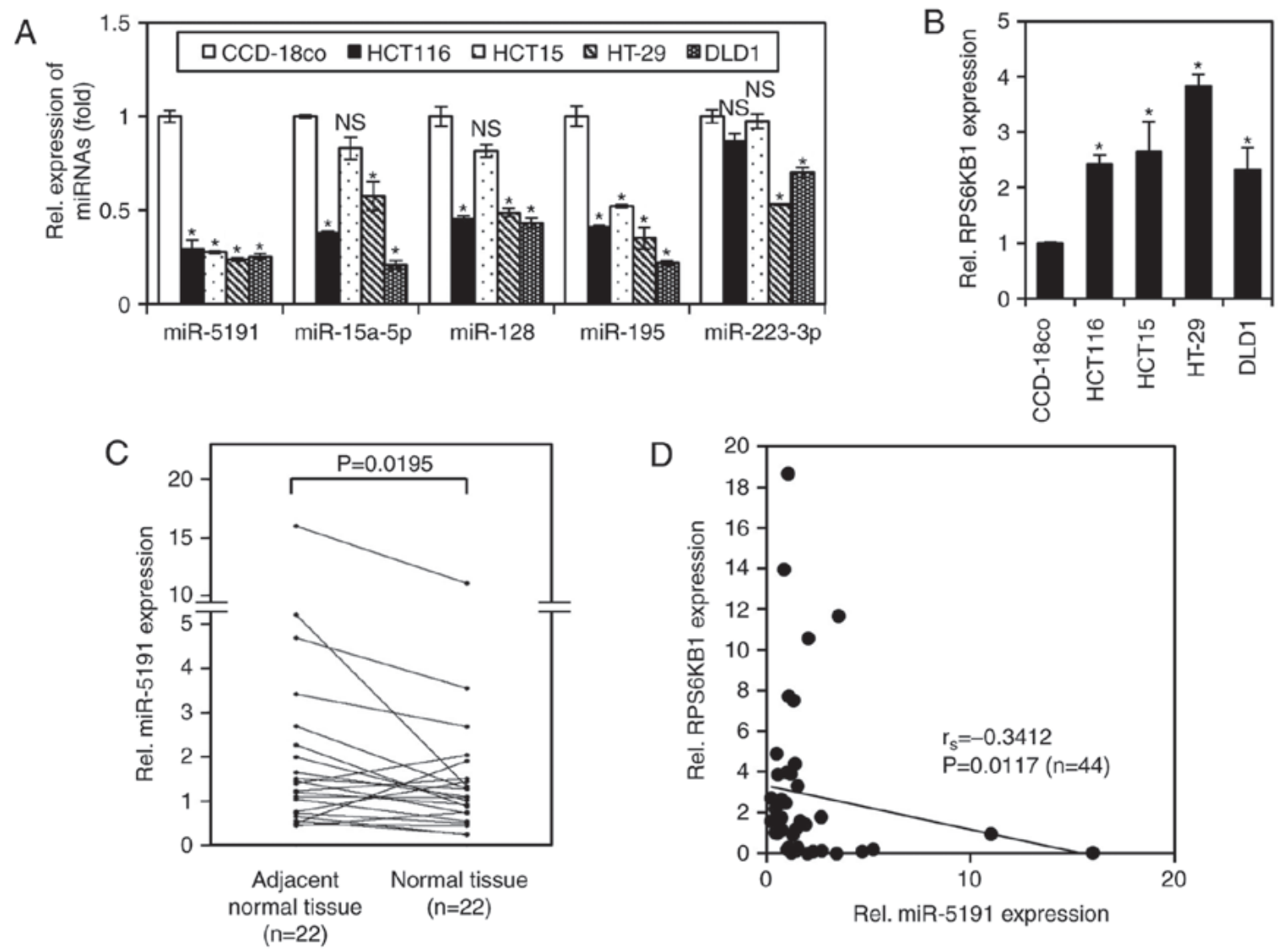

Figure 5. miR-5191 is downregulated in CRC tissues. (A) Comparison of the expression levels of miR-5191 and other RPS6KB1-targeting miRNAs in CRC and normal cell lines. Expression levels of miRNAs were determined via RT-qPCR analysis. P-values were calculated by ANOVA with Tukey's post hoc test. Data are presented as the mean \pm SEM. ${ }^{*} \mathrm{P}<0.05$ vs. Cont $(\mathrm{n}=3)$. (B) Determination of RPS6KB1 mRNA expression levels in CRC and normal cell lines. RT-qPCR analysis was performed using total RNA prepared from CRC and normal cell lines. P-values were calculated by ANOVA with Tukey's post hoc test. Data are presented as the mean \pm SEM. ${ }^{*} \mathrm{P}<0.05$ vs. Cont $(\mathrm{n}=3)$. (C) Comparison of miR-5191 expression levels in tumor and adjacent normal tissues from patients with CRC. P-value was calculated using paired Student's t-test. (D) Inverse correlation between miR-5191 and RPSKB1 expression in patients with CRC. Relative expression levels of miR-5191 and RPSKB1 mRNA were plotted for correlation analysis. $\mathrm{r}_{\mathrm{s}}$ is the correlation coefficient calculated by Spearman analysis. CRC, colorectal cancer; miR/miRNA, microRNA; n.s., not significant; RPS6KB1, ribosomal protein S6 kinase $\beta 1$; RT-qPCR, reverse transcription-quantitative PCR.

miR-5191 expression levels were significantly lower in CRC cell lines (HCT116, HCT15, HT-29 and DLD1) compared with in the colon-derived normal cell line CCD18-co; the expression levels of the other miRNAs were also generally lower in the cancer cell lines, with some variations depending on cell line (Fig. 5A). Similarly, the mRNA expression of RPS6KB1 was upregulated in CRC cell lines compared with in normal cell lines (Fig. 5B).

To validate the clinical relevance of miR-5191 as a tumor suppressor, miR-5191 expression levels were compared between tumor tissues and matched adjacent normal tissues using 22 pairs of frozen specimens from patients with CRC. miR-5191 expression levels were significantly lower in tumor tissues than in matched adjacent normal tissues (Fig. 5C). Furthermore, the correlation between RPS6KB1 and miR-5191 expression levels in the same CRC specimens was evaluated. This revealed a significant inverse correlation between miR-5191 and RPS6KB1 expression in human CRC tissues (Fig. 5D).

miR-5191 inhibits tumor growth in mouse xenografts. To validate the in vivo tumor-suppressive effects of miR-5191, the changes in xenograft tumor volume after miR-5191 delivery were measured. Tumors established using HCT116 cells were injected with control miRNA or miR-5191 in a complex with an in vivo transfection agent. After two injections of miR-5191 with a 3-day interval, the tumor growth rate was significantly slower compared with in the control-injected tumors (Fig. 6A). Additionally, end-point tumor weights of miR-5191-injected mice were significantly reduced compared with those of control-injected mice (Fig. 6B and C). IHC analysis revealed that intratumoral injection of miR-5191 decreased the expression levels of the target protein RPS6KB1 and the cell cycle-associated protein cyclin D1, while increasing the expression of the proapoptotic protein BAD (Fig. 6D). These results indicated that miR-5191 functions as a tumor suppressor in vivo and exhibits potential for application in cancer therapy.

\section{Discussion}

Numerous studies (11-17) have reported that a variety of miRNAs are abnormally expressed in various types of cancers, and serve important roles in cancer development and progression by acting as tumor suppressors or oncogenes. 
A

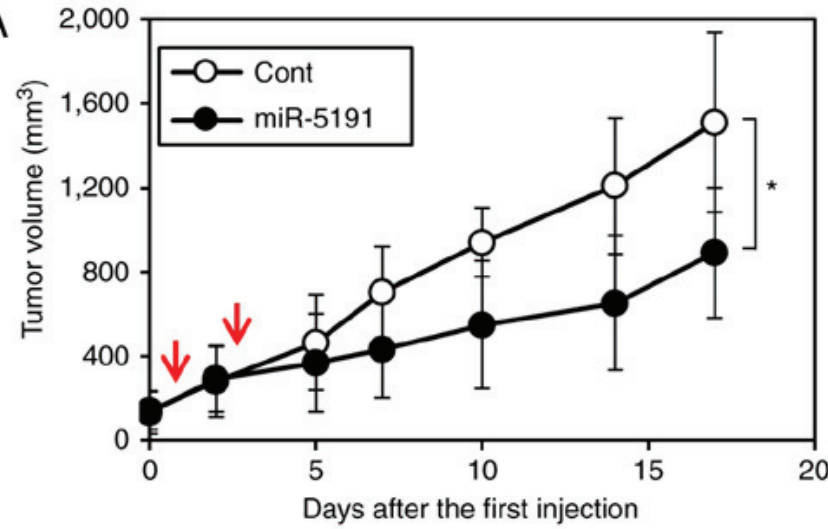

B

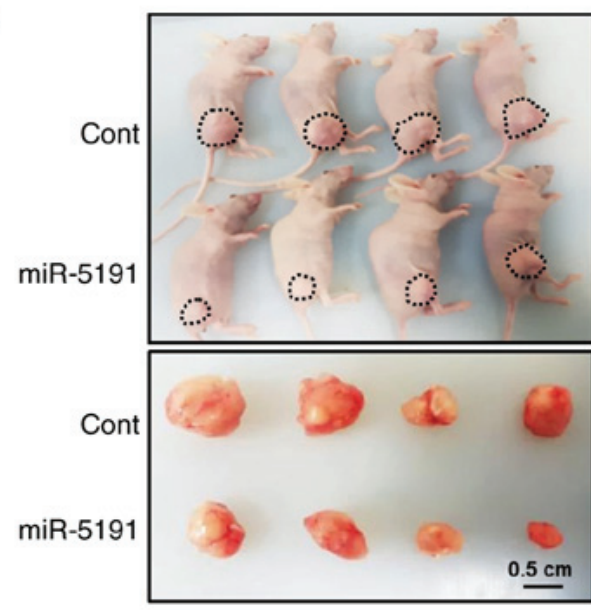

C

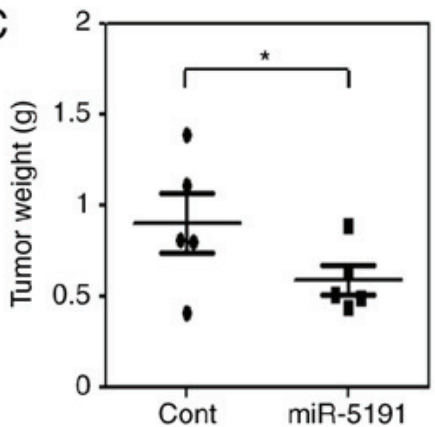

D

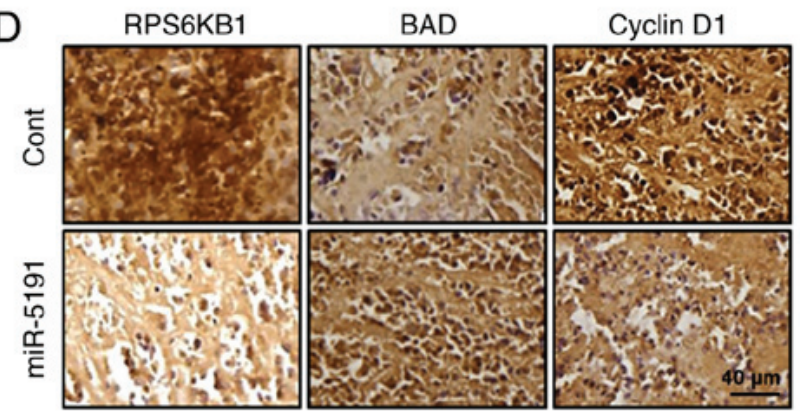

Figure 6. miR-5191 suppresses in vivo tumor growth. (A) miR-5191 suppresses tumor growth in mouse xenografts. Xenograft tumors were generated by subcutaneous injection of HCT116 cells, and miR-5191 $(\mathrm{n}=6)$ or control miRNA $(\mathrm{n}=6)$ was mixed with in vivo-jetPEI and injected into tumors at the indicated time points (red arrows). The tumor sizes were measured at 3-day intervals and plotted. P-values were calculated by ANOVA with repeated measures. Data are presented as the mean \pm SEM. ${ }^{*} \mathrm{P}<0.05$. (B) Representative images of tumor-bearing mice and the removed tumors. (C) Comparison of tumor weight distribution. Tumors were removed from mice when the average tumor volume of control group reached $1600 \mathrm{~mm}^{3}$, and weighed. P-values were calculated by Student's t-test. Data are presented as the mean \pm SEM. * $<0.05$. (D) Immunohistochemical analysis of tumor sections for the expression of RPS6KB1 and relevant proteins. BAD, BCL-2-associated agonist of cell death; Cont, control mi/siRNA; miR/miRNA, microRNA; RPS6KB1, ribosomal protein S6 kinase $\beta 1$.

Thus, it is valuable to discover and characterize novel miRNAs with tumor-suppressive or oncogenic functions, not only for improved understanding of cancer, but also for the development of novel anticancer therapeutic agents. In one such effort, several new tumor-suppressive miRNAs were identified by employing a functional screening approach $(26,27)$. Following this, miR-5191 was characterized as a tumor-suppressive miRNA in the present study.

RPS6KB1, a key effector molecule of PI3K/Akt/mTOR signaling, was identified as a direct target of miR-5191. Importantly, the targeting of RPS6KB1 by miR-5191 suppressed various tumorigenic characteristics of CRC cells. RPS6KB1 is one of the most well-known downstream targets of mTOR complex 1 (mTORC1). Activated mTORC1 directly phosphorylates RPS6KB1 to regulate a variety of biological processes such as translational initiation, cell cycle progression and cell survival $(9,45)$. Abnormal activation of PI3K/Akt signaling is common in CRCs $(46,47)$, and numerous studies have shown that modulation of $\mathrm{PI} 3 \mathrm{~K} / \mathrm{Akt} / \mathrm{mTOR}$ signaling may provide therapeutic efficacy for cancer treatment (48-50). mTOR is a serine/threonine kinase that is activated in response to various stimuli through $\mathrm{PI} 3 \mathrm{~K} / \mathrm{Akt}$, and is present in multiprotein complexes with mTORC1 and mTORC2 $(51,52)$. Several studies have shown that various miRNAs contribute to preventing tumorigenesis by targeting various steps of the PI3K/Akt/mTOR pathway, including RPS6KB1. For example, miR-99 inhibits PI3K by targeting insulin-like growth factor (IGF)/(IGF) receptor in hepatocellular carcinoma (53). miR-218 suppresses tumor cell invasion and migration by targeting phosphatidylinositol 4-phosphate 3-kinase C2 domain-containing a polypeptide and PI3K regulatory subunit 1 in CRC cells (54). miR-100 inhibits tumorigenesis by directly targeting mTOR in bladder cancer (55), and miR-199a-3p induces cell cycle arrest and apoptosis by targeting mTOR in hepatocellular carcinoma (56). Furthermore, miR-195, miR-15/16, miR-223 and miR-128 have been reported to suppress various types of cancers by directly targeting RPS6KB1 (22-25). These reports suggest that targeting RPS6KB1 or upstream components of mTOR signaling is a plausible strategy for the development of anticancer therapies. It was demonstrated in the present study that miR-5191 inhibits not only monolayer CRC cell proliferation, by inducing apoptosis and cell cycle arrest, but also invasion, spheroid growth, and organoid growth. These inhibitory functions of miR-5191 were suppressed by overexpression of RPS6KB1, indicating that targeting RPS6KB1 is a central mechanism for the tumor-suppressive functions of miR-5191. Our results are consistent with previous reports showing the diverse tumor-suppressive functions of miRNAs targeting RPS6KB1 (22-25). In contrast, the observation 
that miR-5191 exhibited further tumor-suppressive effect in RPS6KB1-depleted cells suggested that the tumor-suppressive function of miR-5191 may not be entirely dependent on RPS6KB1 targeting, but also involves targeting of other proteins. These additional mechanisms remain to be pursued in future studies.

In vasiveness, spheroid growth and organoid growth are features of aggressive CSC-like cells, which exhibit resistance to treatments and are widely accepted to be the major causes of cancer recurrence. Thus, the present findings showing inhibition of these CSC features by miR-5191 suggest that miR-5191 is an efficient tumor-suppressive miRNA that can be utilized as a promising candidate for the development of potent miRNA therapeutics to overcome obstacles to CRC therapy. Increasing the abundance of tumor-suppressive miRNAs in tumors is a good approach for the development of anticancer miRNA therapeutics. Furthermore, the antitumor effects of miR-5191 were verified in a mouse xenograft model. Similar to the in vitro function, intratumorally-injected miR-5191 effectively suppressed tumor growth and target gene expression. Taken together, these results demonstrated the potential of miR-5191 as a miRNA therapeutic with anticancer function.

In accordance with the tumor-suppressive function of miR-5191, the expression of miR-5191 was found to be downregulated in CRC tumor tissues as well as in cancer cells, when compared with adjacent normal tissues and normal cells, respectively. An inverse correlation between miR-5191 and RPS6KB1 expression in CRC tumor tissues further supported the in vitro data indicating that miR-5191 functioned by targeting RPS6KB1. At present, little is known regarding the mechanisms underlying the regulation of miR-5191 expression. However, it was observed that treatment with DNA methylation inhibitor 5-aza-2'-deoxycytidine, histone deacetylase inhibitor trichostatin A or TGF- $\beta$ did not alter the expression of miR-5191 in CRC cells (data not shown). This suggests that epigenetic regulation by DNA methylation or histone acetylation is not involved in the regulation of miR-5191 expression. The mechanism via which miR-5191 expression is regulated requires demonstration in future studies and will provide novel insight into the mechanistic role of miR-5191 in cancer physiology. While this is the first report on the tumor-suppressive function and downregulation of miR-5191 in CRC, one study has described the expression levels of miR-5191 in salivary adenoid cystic carcinoma (SACC) cells (57). In their study, miR-5191 was identified as one of the miRNAs that w significantly downregulated in a highly metastatic variant of SACC cells, implicating a potential inhibitory role of miR-5191 during metastatic progression of SACC. This raises the possibility that the tumor-suppressive function and potential therapeutic potential of miR-5191 can be extended to various other cancer types.

\section{Acknowledgements}

Not applicable.

\section{Funding}

This work was supported by a grant of the Korea Institute of Radiological and Medical Sciences, funded by the Ministry of Science and ICT, Republic of Korea (grant no. 50531-2019) and in part by a grant from the National Research Foundation of Korea (grant no. NRF-2017R1A2B2004055 to YHH).

\section{Availability of data and materials}

All data generated or analyzed during current study are included in this published article.

\section{Authors' contributions}

HJA and MP performed the experiments. HJA, MP, JK and YHH planned the experiments, analyzed data and interpreted the results. HJA and $\mathrm{YHH}$ drafted the manuscript. $\mathrm{YHH}$ designed and oversaw the entire study. All authors read and approved the final manuscript for publication.

\section{Ethics approval and consent to participate}

The mice used in the present study were maintained according to guidelines approved by the Institutional Animal Care and Use Committee of Korea Institute of Radiological and Medical Sciences (KIRAMS; permit no. 2017-0056), and were conducted according to AVMA guidelines. Collection and use of CRC patient specimens were approved by the Institutional Review Board (IRB) of KIRAMS (IRB no. K-1610-002-003). For organoid culture, surgical human colonic tissues were obtained from Korea Cancer Center Hospital in KIRAMS after informed consent was provided, and the study was approved by the IRB of KIRAMS (IRB no. 2017-07-001). The study was conducted in accordance with the Declaration of Helsinki.

\section{Patient consent for publication}

The present study obtained consent for publication from all patients.

\section{Competing interests}

The authors declare that there are no competing interests.

\section{References}

1. Siegel RL, Miller KD and Jemal A: Cancer statistics, 2017. CA Cancer J Clin 67: 7-30, 2017.

2. Fearon ER: Molecular genetics of colorectal cancer. Annu Rev Pathol 6: 479-507, 2011.

3. Cancer Genome Atlas Network: Comprehensive molecular characterization of human colon and rectal cancer. Nature 487: 330-337, 2012.

4. Easton JB and Houghton PJ: mTOR and cancer therapy. Oncogene 25: 6436-6446, 2006.

5. Pópulo H, Lopes JM and Soares P: The mTOR signalling pathway in human cancer. Int J Mol Sci 13: 1886-1918, 2012.

6. Ilagan E and Manning BD: Emerging role of mTOR in the response to cancer therapeutics. Trends Cancer 2: 241-251, 2016.

7. Showkat M, Beigh MA and Andrabi KI: mTOR signaling in protein translation regulation: Implications in cancer genesis and therapeutic interventions. Mol Biol Int 2014: 686984, 2014.

8. Kurgan N, Tsakiridis E, Kouvelioti R, Moore J, Klentrou P and Tsiani E: Inhibition of human lung cancer cell proliferation and survival by Post-exercise serum is associated with the inhibition of Akt, mTOR, p70 S6K, and Erk1/2. Cancers (Basel) 9: pii: E46, 2017. 
9. Wang H, Duan L, Zou Z, Li H, Yuan S, Chen X, Zhang Y, Li X, Sun H, Zha H, et al: Activation of the PI3K/Akt/mTOR/p70S6K pathway is involved in S100A4-induced viability and migration in colorectal cancer cells. Int J Med Sci 11: 841-849, 2014.

10. Holz MK: The role of S6K1 in ER-positive breast cancer. Cell Cycle 11: 3159-3165, 2012.

11. Gao J, Zhang Q, Xu J, Guo L and Li X: Clinical significance of serum miR-21 in breast cancer compared with CA153 and CEA. Chin J Cancer Res 25: 743-748, 2013.

12. Hamam R, Hamam D, Alsaleh KA, Kassem M, Zaher W, Alfayez M, Aldahmash A and Alajez NM: Circulating microRNAs in breast cancer: Novel diagnostic and prognostic biomarkers. Cell Death Dis 8: e3045, 2017.

13. Rabinowits G, Gerçel-Taylor C, Day JM, Taylor DD and Kloecker GH: Exosomal microRNA: A diagnostic marker for lung cancer. Clin Lung Cancer 10: 42-46, 2009.

14. Wu X, Piper-Hunter MG, Crawford M, Nuovo GJ, Marsh CB, Otterson GA and Nana-Sinkam SP: MicroRNAs in the pathogenesis of lung cancer. J Thorac Oncol 4: 1028-1034, 2009.

15. Slattery ML, Lee FY, Pellatt AJ, Mullany LE, Stevens JR, Samowitz WS, Wolff RK and Herrick JS: Infrequently expressed miRNAs in colorectal cancer tissue and tumor molecular phenotype. Mod Pathol 30: 1152-1169, 2017.

16. Toyota M,Suzuki H, Sasaki Y, Maruyama R, Imai K, Shinomura Y and Tokino T: Epigenetic silencing of microRNA-34b/c and $\mathrm{B}$-cell translocation gene 4 is associated with $\mathrm{CpG}$ island methylation in colorectal cancer. Cancer Res 68: 4123-4132, 2008.

17. Hermeking H: The miR-34 family in cancer and apoptosis. Cell Death Differ 17: 193-199, 2010.

18. Xi L, Zhang Y, Kong S and Liang W: miR-34 inhibits growth and promotes apoptosis of osteosarcoma in nude mice through targetly regulating TGIF2 expression. Biosci Rep 38: pii: BSR20180078, 2018.

19. Li XJ, Ren ZJ and Tang JH: MicroRNA-34a: A potential therapeutic target in human cancer. Cell Death Dis 5: e1327, 2014

20. Cimmino A, Calin GA, Fabbri M, Iorio MV, Ferracin M, Shimizu M, Wojcik SE, Aqeilan RI, Zupo S, Dono M, et al: miR-15 and miR-16 induce apoptosis by targeting BCL2. Proc Natl Acad Sci USA 102: 13944-13949, 2005

21. Yu S, Lu Z, Liu C, Meng Y, Ma Y, Zhao W, Liu J, Yu J and Chen J: miRNA-96 suppresses KRAS and functions as a tumor suppressor gene in pancreatic cancer. Cancer Res 70: 6015-6025, 2010

22. Cai C, Chen QB, Han ZD, Zhang YQ, He HC, Chen JH, Chen YR, Yang SB, Wu YD, Zeng YR, et al: miR-195 inhibits tumor progression by targeting RPS6KB1 in Human prostate cancer. Clin Cancer Res 21: 4922-4934, 2015.

23. Janaki Ramaiah M, Lavanya A, Honarpisheh M, Zarea M, Bhadra U and Bhadra MP: MiR-15/16 complex targets p70S6 kinase 1 and controls cell proliferation in MDA-MB-231 breast cancer cells. Gene 552: 255-264, 2014

24. Dai GH, Ma PZ, Song XB, Liu N, Zhang T and Wu B MicroRNA-223-3p inhibits the angiogenesis of ischemic cardiac microvascular endothelial cells via affecting RPS6KB1/hif-1a signal pathway. PLoS One 9: e108468, 2014.

25. Shi ZM, Wang J, Yan Z, You YP, Li CY, Qian X, Yin Y, Zhao P, Wang YY, Wang XF, et al: MiR-128 inhibits tumor growth and angiogenesis by targeting p70S6K1. PLoS One 7: e32709, 2012.

26. An HJ, Kwak SY, Yoo JO, Kim JS, Bae IH, Park MJ, Cho MY, Kim J and Han YH: Novel miR-5582-5p functions as a tumor suppressor by inducing apoptosis and cell cycle arrest in cancer cells through direct targeting of GAB1, SHC1, and CDK2 Biochim Biophys Acta 1862: 1926-1937, 2016

27. Choe MH, Yoon Y, Kim J, Hwang SG, Han YH and Kim JS miR-550a-3-5p acts as a tumor suppressor and reverses BRAF inhibitor resistance through the direct targeting of YAP. Cell Death Dis 9: 640, 2018

28. Kwak SY, Yoo JO, An HJ, Bae IH, Park MJ, Kim J and Han YH: miR-5003-3p promotes epithelial-mesenchymal transition in breast cancer cells through Snail stabilization and direct targeting of E-cadherin. J Mol Cell Biol: Jun 9, 2016 (Epub ahead of print).

29. Yoo JO, Kwak SY, An HJ, Bae IH, Park MJ and Han YH: miR-181b-3p promotes epithelial-mesenchymal transition in breast cancer cells through Snail stabilization by directly targeting YWHAG. Biochim Biophys Acta 1863: 1601-1611, 2016.

30. Kozomara A and Griffiths-Jones S: miRBase: Integrating microRNA annotation and deep-sequencing data. Nucleic Acids Res 39 (Database Issue): D152-D157, 2011.
31. Livak KJ and Schmittgen TD: Analysis of relative gene expression data using real-time quantitative PCR and the 2(-Delta Delta C(T)) method. Methods 25: 402-408, 2001.

32. Sato T, Stange DE, Ferrante M, Vries RG, Van Es JH, Van den Brink S, Van Houdt WJ, Pronk A, Van Gorp J, Siersema PD and Clevers H: Long-term expansion of epithelial organoids from human colon, adenoma, adenocarcinoma, and Barrett's epithelium. Gastroenterology 141: 1762-1772, 2011.

33. Grabinger T, Luks L, Kostadinova F, Zimberlin C, Medema JP, Leist $M$ and Brunner T: Ex vivo culture of intestinal crypt organoids as a model system for assessing cell death induction in intestinal epithelial cells and enteropathy. Cell Death Dis 5: e1228, 2014.

34. Vlachos IS, Kostoulas N, Vergoulis T, Georgakilas G, Reczko M, Maragkakis M, Paraskevopoulou MD, Prionidis K, Dalamagas T and Hatzigeorgiou AG: DIANA miRPath v.2.0: Investigating the combinatorial effect of microRNAs in pathways. Nucleic Acids Res 40: W498-W504, 2012.

35. Agarwal V, Bell GW, Nam JW and Bartel DP: Predicting effective microRNA target sites in mammalian mRNAs. Elife: 4, 2015 doi: 10.7554/eLife.05005.

36. Wong N and Wang X: miRDB: An online resource for microRNA target prediction and functional annotations. Nucleic Acids Res 43 (Database Issue): D146-D152, 2015.

37. Park SY, Lee JH, Ha M, Nam JW and Kim VN: miR-29 miRNAs activate p53 by targeting p 85 alpha and CDC42. Nat Struct Mol Biol 16: 23-29, 2009.

38. Shaheen S, Ahmed M, Lorenzi F and Nateri AS: Spheroid-formation (Colonosphere) assay for in vitro assessment and expansion of stem cells in colon cancer. Stem Cell Rev 12: 492-499, 2016

39. Shimono Y, Mukohyama J, Isobe T, Johnston DM, Dalerba P and Suzuki A: Organoid culture of human cancer stem cells. Methods Mol Biol: Sep 22, 2016 (Epub ahead of print).

40. Crespo M, Vilar E, Tsai SY, Chang K, Amin S, Srinivasan T, Zhang T, Pipalia NH, Chen HJ, Witherspoon M, et al: Colonic organoids derived from human induced pluripotent stem cells for modeling colorectal cancer and drug testing. Nat Med 23: 878-884, 2017.

41. Hubert CG, Rivera M, Spangler LC, Wu Q, Mack SC, Prager BC, Couce M, McLendon RE, Sloan AE and Rich JN: A Three-dimensional organoid culture system derived from human glioblastomas recapitulates the hypoxic gradients and cancer stem cell heterogeneity of tumors found in vivo. Cancer Res 76: 2465-2477, 2016 .

42. Thompson EW, Newgreen DF and Tarin D: Carcinoma invasion and metastasis: A role for epithelial-mesenchymal transition? Cancer Res 65: 5991-5995, 2005.

43. Amaral CL, Freitas LB, Tamura RE, Tavares MR, Pavan IC, Bajgelman MC and Simabuco FM: S6Ks isoforms contribute to viability, migration, docetaxel resistance and tumor formation of prostate cancer cells. BMC Cancer 16: 602, 2016.

44. Fu YP, Edvardsen H, Kaushiva A, Arhancet JP, Howe TM, Kohaar I, Porter-Gill P, Shah A, Landmark-Høyvik H, Fosså SD, et al: NOTCH2 in breast cancer: Association of SNP rs11249433 with gene expression in ER-positive breast tumors without TP53 mutations. Mol Cancer 9: 113, 2010.

45. Ekim B, Magnuson B, Acosta-Jaquez HA, Keller JA, Feener EP and Fingar DC: mTOR kinase domain phosphorylation promotes mTORC1 signaling, cell growth, and cell cycle progression. Mol Cell Biol 31: 2787-2801, 2011.

46. Danielsen SA, Eide PW, Nesbakken A, Guren T, Leithe E and Lothe RA: Portrait of the PI3K/AKT pathway in colorectal cancer. Biochim Biophys Acta 1855: 104-121, 2015.

47. Zhang T, Ma Y, Fang J, Liu C and Chen L: A deregulated PI3K-AKT signaling pathway in patients with colorectal cancer. J Gastrointest Cancer 50: 35-41, 2019.

48. Johnson SM, Gulhati P, Rampy BA, Han Y, Rychahou PG, Doan HQ, Weiss HL and Evers BM: Novel expression patterns of PI3K/Akt/mTOR signaling pathway components in colorectal cancer. J Am Coll Surg 210: 767-778, 2010.

49. Crowell JA, Steele VE and Fay JR: Targeting the AKT protein kinase for cancer chemoprevention. Mol Cancer Ther 6: 2139-2148, 2007.

50. Bitting RL and Armstrong AJ: Targeting the PI3K/Akt/mTOR pathway in castration-resistant prostate cancer. Endocr Relat Cancer 20: R83-R99, 2013.

51. Hassan B, Akcakanat A, Holder AM and Meric-Bernstam F: Targeting the PI3-kinase/Akt/mTOR signaling pathway. Surg Oncol Clin N Am 22: 641-664, 2013. 
52. Soliman GA: The role of mechanistic target of rapamycin (mTOR) complexes signaling in the immune responses. Nutrients 5: 2231-2257, 2013

53. Li D, Liu X, Lin L, Hou J, Li N, Wang C, Wang P, Zhang Q, Zhang P, Zhou W, et al: MicroRNA-99a inhibits hepatocellular carcinoma growth and correlates with prognosis of patients with hepatocellular carcinoma. J Biol Chem 286: 36677-36685, 2011.

54. Zhang X, Shi H, Tang H, Fang Z, Wang J and Cui S: miR-218 inhibits the invasion and migration of colon cancer cells by targeting the $\mathrm{PI} 3 \mathrm{~K} / \mathrm{Akt} / \mathrm{mTOR}$ signaling pathway. Int J Mol Med 35: 1301-1308, 2015.
55. Xu C, Zeng Q, Xu W, Jiao L, Chen Y, Zhang Z, Wu C, Jin T, Pan A, Wei R, et al: miRNA-100 inhibits human bladder urothelial carcinogenesis by directly targeting mTOR. Mol Cancer Ther 12: 207-219, 2013.

56. Fornari F, Milazzo M, Chieco P, Negrini M, Calin GA, Grazi GL, Pollutri D, Croce CM, Bolondi L and Gramantieri L: MiR-199a-3p regulates $\mathrm{mTOR}$ and $\mathrm{c}-\mathrm{Met}$ to influence the doxorubicin sensitivity of human hepatocarcinoma cells. Cancer Res 70: 5184-5193, 2010.

57. Chen W, Zhao X, Dong Z, Cao G and Zhang S: Identification of microRNA profiles in salivary adenoid cystic carcinoma cells during metastatic progression. Oncol Lett 7: 2029-2034, 2014. 